\title{
The Application of Vertebral Augmentation Procedures and Teriparatide in the Treatment of Osteoporotic Vertebral Compression Fractures [Response to Letter]
}

This article was published in the following Dove Press journal: Clinical Interventions in Aging

Meng Kong (iD)

Chuanli Zhou

Xuexiao $\mathrm{Ma}$

Department of Spinal Surgery, Affiliated Hospital of Qingdao University, Qingdao, Shandong Province 266000, People's Republic of China
Correspondence: Xuexiao Ma Department of Spinal Surgery, Affiliated Hospital of Qingdao University, No. 59, Hai Er Road, Qingdao, Shandong Province 266000, People's Republic of China

$\mathrm{Tel}+8653218661807895$

Email ma_xuexiao@I26.com

\section{Dear editor}

With the attempt to explore a reasonable treatment strategy, we presented the positive effectiveness of teriparatide (TPTD) administration in improving quality of life (QOL) and reducing the incidence of new vertebral compression fractures (NVCFs) after percutaneous kyphoplasty (PKP). ${ }^{1}$ Being interested with the comment opinion proposed by Zhou et al, we would like to put forward our views.

Short-term (eg pain relief, restoration of mechanical stability, mobility improvement and fracture healing) and long-term achievements (eg progressive QOL improvement and prevention of NVCFs) need to be realized in strategies for patients who suffered osteoporotic vertebral compression fractures (OVCFs) ${ }^{2,3}$

Vertebral augmentation procedures (VAP), ie percutaneous vertebroplasty (PVP) and/or PKP, is a minimally invasive therapy adopted in the treatment of OVCFs with the aim of prior pain alleviation by stabilizing the vertebral fracture and recovery of function by restoring vertebral body height (VBH). ${ }^{4}$ Literature reported that PVP/PKP quickly restored patients' walking ability soon after operation and improved QOL in the early stage of OVCFs. ${ }^{5}$ On the other hand, except for the well-known complications induced by surgical procedures, ${ }^{6}$ recurrent fractures and the adjacent vertebral fractures are important issues related to VAPs. Logistic regression analysis showed that VAP was a risk factor of vertebra refracture because of increased local vertebral stiffness. ${ }^{7,8}$ And this procedure has no contribution to bone healing and the treatment of primary disease, ie osteoporosis. Studies have reported high incidence, up to $21.7 \%$, of new symptomatic compression fractures 1 year after percutaneous vertebroplasty. ${ }^{9}$

Routine therapeutic options in conservative treatment for OVCFs should include bed rest with followed short-term back brace wear and anti-osteoporosis drugs to avoid further pathologic vertebral collapse. ${ }^{10}$ As a bone anabolic drug, TPTD exerts positive effects in the treatment of severe osteoporosis, which was acknowledged as another significant risk factor of NVCFs. ${ }^{7}$ Although previous studies have already demonstrated TPTD's effects in terms of gradual pain control and health quality recovery in early stage of OVCFs by enhancing bone formation and bone healing, ${ }^{11}$ whether this slower method could maintain vertebral morphology is one concern. To lower the risks of pulmonary dysfunction, deep vein thrombosis, muscle atrophy, pressure sores, and 
inhibit further demineralization, time in bed should not be too long, which may predispose to future collapse. Whereas the medium- and long-term effect (more than 6 months) of separate TPTD application in strengthening the fractured vertebrae to be stabilized is proven. ${ }^{12}$

In conclusion, VAP provides the ability of immediate pain alleviation, short-term QOL improvement, VBH restoration and spinal deformity correction, ${ }^{13}$ and TPTD administration leads to enhanced acute stage bone healing, reduced progressive collapse and gradual pain relief, ${ }^{14}$ which seems more like a complementary effect. In our opinion, supplemental TPTD treatment is highly recommended following a PVP or PKP procedure.

To some extent, we agree with the comment that TPTD could replace percutaneous vertebral augmentation in OVCFs in appropriate patients. As a kind of medical (conservative) option, TPTD should be applied immediately after the phase of fracture begins, rather than after the failure of other conservative methods. ${ }^{15,16}$ It should also be noted that for patients with high levels of pain, severe osteoporosis, advanced age, overweight, high modified frailty index $(\mathrm{mFI})^{17}$ and intravertebral cleft (IVC), VAP with subsequent TPTD treatment are mostly considered appropriate, since these are risk factors of the failure of conservative treatment of acute OVCFs. ${ }^{2,18}$ In general, studies reporting that the conservative treatment strategy of TPTD obtained similar therapeutic effects with VAP in the treatment of acute OVCFs are limited, ${ }^{11}$ and more research is needed, including more clearly defined participant selection criteria and study protocols.

\section{Acknowledgments}

The authors acknowledge Shuo Han, Chao Wang, Chen Peng, and Ronghuan Wang (Department of Spinal Surgery, Affiliated Hospital of Qingdao University) for their contributions to this communication.

\section{Disclosure}

The authors report no conflicts of interest in this communication.

\section{References}

1. Kong M, Zhou C, Zhu K, et al. 12-month teriparatide treatment reduces new vertebral compression fractures incidence and back pain and improves quality of life after percutaneous kyphoplasty in osteoporotic women. Clin Interv Aging. 2019;14:1693-1703. doi:10. 2147/CIA.S224663

2. Luthman S, Widen J, Borgstrom F. Appropriateness criteria for treatment of osteoporotic vertebral compression fractures. Osteoporos Int. 2018;29(4):793-804. doi:10.1007/s00198-017-4348-x
3. Li HM, Zhang RJ, Gao H, et al. New vertebral fractures after osteoporotic vertebral compression fracture between balloon kyphoplasty and nonsurgical treatment PRISMA. Medicine. 2018;97(40): e12666. doi:10.1097/MD.0000000000012666

4. Amer S, Linda N, Fouad IEK, Gaby K, Rami ER. Vertebral augmentation: state of the art. Asian Spine J. 2016;10(2):370-376.

5. Klazen CAH, Lohle PNM, Vries JD, Jansen FH, Lancet WP. Vertebroplasty versus conservative treatment in acute osteoporotic vertebral compression fractures (Vertos II): an open-label randomised trial. Lancet (London, England). 2010;376(9746):1085-1092. doi:10.1016/S0140-6736(10)60954-3

6. Cosar M, Sasani M, Oktenoglu T, et al. The major complications of transpedicular vertebroplasty. J Neurosurg Spine. 2009:11 (5):607-613.

7. Li YX, Guo DQ, Zhang SC, et al. Risk factor analysis for re-collapse of cemented vertebrae after percutaneous vertebroplasty (PVP) or percutaneous kyphoplasty (PKP). Int Orthop. 2018;42 (9):2131-2139. doi:10.1007/s00264-018-3838-6

8. Liu J, Yu LJ, Song HP, Lu JW, Liu H, Zhang C. [Analysis of correlative factors of non-surgical vertebral fractures after percutaneous vertebroplasty for osteoporotic vertebral compression fractures]. Zhongguo Gu Shang. 2013;26(3):190-193.

9. Syed MI, Patel NA, Jan S, Harron MS, Morar K, Shaikh A. New symptomatic vertebral compression fractures within a year following vertebroplasty in osteoporotic women. AJNR Am J Neuroradiol. 2005;26(6):1601-1604.

10. Mattie R, Laimi K, Yu S, Saltychev M. Comparing percutaneous vertebroplasty and conservative therapy for treating osteoporotic compression fractures in the thoracic and lumbar spine: a systematic review and meta-analysis. J Bone Joint Surg Am. 2016;98(12):1041-1051. doi:10.2106/JBJS.15.00425

11. Ma Y, Wu X, Xiao X, et al. Effects of teriparatide versus percutaneous vertebroplasty on pain relief, quality of life and cost-effectiveness in postmenopausal females with acute osteoporotic vertebral compression fracture: a prospective cohort study. Bone. 2019;131:115154. doi:10.1016/j.bone.2019.115154

12. Zhao Y, Xue R, Shi N, et al. Aggravation of spinal cord compromise following new osteoporotic vertebral compression fracture prevented by teriparatide in patients with surgical contraindications. Osteoporos Int. 2016;27(11):3309-3317. doi:10.1007/s00198-016-3651-2

13. Taylor RS, Taylor RJ, Fritzell P. Balloon kyphoplasty and vertebroplasty for vertebral compression fractures: a comparative systematic review of efficacy and safety. Spine. 2006;31(23):2747-2755. doi:10.1097/01.brs.0000244639.71656.7d

14. Kitaguchi K, Kashii M, Ebina K, et al. Effects of weekly teriparatide administration for vertebral stability and bony union in patients with acute osteoporotic vertebral fractures. Asian Spine J. 2019;13 (5):763-771. doi:10.31616/asj.2018.0311

15. Shigenobu K, Hashimoto T, Kanayama M, Ohha H, Yamane S. The efficacy of osteoporotic treatment in patients with new spinal vertebral compression fracture pain, ADL, QOL, bone metabolism and fracture-healing - In comparison with weekly teriparatide with bisphosphonate. Bone Rep. 2019;11:100217. doi:10.1016/j.bonr. 2019.100217

16. McGraw JK, Cardella J, Barr JD, et al. Society of interventional radiology quality improvement guidelines for percutaneous vertebroplasty. J Vasc Interv Radiol. 2003;14(7):827-831. doi:10.10 16/S1051-0443(07)60242-5

17. Velanovich V, Antoine H, Swartz A, Peters D, Rubinfeld I. Accumulating deficits model of frailty and postoperative mortality and morbidity: its application to a national database. J Surg Res. 2013;183(1):104-110. doi:10.1016/j.jss.2013.01.021

18. Zhang J, He X, Fan Y, Du J, Hao D. Risk factors for conservative treatment failure in acute osteoporotic vertebral compression fractures (OVCFs). Arch Osteoporos. 2019;14(1):24. doi:10.1007/ s11657-019-0563-8 
Dove Medical Press encourages responsible, free and frank academic debate. The content of the Clinical Interventions in Aging 'letters to the editor' section does not necessarily represent the views of Dove Medical Press, its officers, agents, employees, related entities or the Clinical Interventions in Aging editors. While all reasonable steps have been taken to confirm the content of each letter, Dove Medical Press accepts no liability in respect of the content of any letter, nor is it responsible for the content and accuracy of any letter to the editor.

Clinical Interventions in Aging

Dovepress

\section{Publish your work in this journal}

Clinical Interventions in Aging is an international, peer-reviewed journal focusing on evidence-based reports on the value or lack thereof of treatments intended to prevent or delay the onset of maladaptive correlates of aging in human beings. This journal is indexed on PubMed Central, MedLine, CAS, Scopus and the Elsevier
Bibliographic databases. The manuscript management system is completely online and includes a very quick and fair peer-review system, which is all easy to use. Visit http://www.dovepress.com/ testimonials.php to read real quotes from published authors. 